Review Article

\title{
A State-of-the-Art Review on Fatigue Life Assessment of Steel Bridges
}

\author{
X. W. Ye, ${ }^{1}$ Y. H. Su, ${ }^{2}$ and J. P. Han ${ }^{2}$ \\ ${ }^{1}$ Department of Civil Engineering, Zhejiang University, Hangzhou 310058, China \\ ${ }^{2}$ Key Laboratory of Disaster Prevention and Mitigation in Civil Engineering of Gansu Province, Lanzhou University of Technology, \\ Lanzhou 730050, China
}

Correspondence should be addressed to X. W. Ye; cexwye@zju.edu.cn

Received 15 October 2013; Revised 23 December 2013; Accepted 29 December 2013; Published 10 February 2014

Academic Editor: Stathis C. Stiros

Copyright (C) 2014 X. W. Ye et al. This is an open access article distributed under the Creative Commons Attribution License, which permits unrestricted use, distribution, and reproduction in any medium, provided the original work is properly cited.

Fatigue is among the most critical forms of damage potentially occurring in steel bridges, while accurate assessment or prediction of the fatigue damage status as well as the remaining fatigue life of steel bridges is still a challenging and unsolved issue. There have been numerous investigations on the fatigue damage evaluation and life prediction of steel bridges by use of deterministic or probabilistic methods. The purpose of this review is devoted to presenting a summary on the development history and current status of fatigue condition assessment of steel bridges, containing basic aspects of fatigue, classical fatigue analysis methods, data-driven fatigue life assessment, and reliability-based fatigue condition assessment.

\section{Introduction}

Fatigue is a localized and progressive process in which structural damage accumulates continuously due to the repetitive application of external loadings such as vehicles for steel bridges, winds for high-rise buildings, waves for offshore platforms, and temperature for turbine engines, while these applied loadings may be well below the structural resistance capacity. This kind of process is extraordinarily dangerous because a single application of the load would not create any abnormal effects, whereas a conventional structural stress analysis might lead to a conclusion of safety that does not exist. Over a long period of time, the strength and serviceability modes of failure have been well investigated in the professional engineering communities. However, as one of the most critical forms of damage and principal failure modes for steel structures, fatigue is still less understood in terms of the cause of formation and failure mechanism. It is therefore essential to seek novel methodologies and develop advanced technologies for seizing the fatigue phenomenon and conducting reliable assessment of fatigue damage status of steel bridges which serve as vital components in the transportation infrastructure of a nation.
Two approaches are commonly employed for fatigue damage evaluation and life prediction of bridge structures. The first approach is the traditional $S-N$ curve method, in which the relationship between the constant-amplitude stress range, $S$, and the number of cycles to failure, $N$, is determined by appropriate fatigue experiments and described by an $S-N$ curve. The Palmgren-Miner linear damage hypothesis, also called Miner's rule [1], extends this approach to variable-amplitude loadings. The second method is the fracture mechanics approach which is dominantly dedicated to exploring the features and disciplines of crack initiation and growth in consideration of stress field at the crack tip. In general, the two approaches are applied sequentially, with the $S-N$ curve method being used at the bridge design stage or preliminary evaluation of fatigue life and the fracture mechanics approach for more refined crack-based remaining fatigue life assessment or effective decision-making on inspection and maintenance strategies [2].

There have been a lot of investigations and applications on fatigue damage evaluation and life prediction of bridge structures using the traditional $S-N$ method or the fracture mechanics approach. Some specifications [3-5] adopt the traditional nominal $S-N$ method to guide bridge fatigue 
design or evaluation. According to these specifications, the fatigue life prediction of stochastically loaded structures is to determine the correlation between the stress spectrum and the material endurance. The material endurance is generally given in the form of $S$ - $N$ curves for constant-amplitude loadings. The stress spectrum is generally unknown and needs to be evaluated by means of experiments or simulations. In the process of fatigue life prediction, the stress spectrum is derived by extracting the stress cycles from a measured or simulated stress time history with a suitable cycle counting method. Next, a proper fatigue damage accumulative rule is chosen and the fatigue damage caused by individual stress cycle is calculated. The total fatigue damage equals the sum of damage resulting from individual stress cycle. One of the most widely used damage accumulative rules is the Miner's rule, and a rainflow cycle counting method is generally used for extracting the stress cycles from the stress time histories $[6,7]$.

The nature of fatigue process and uncertainties associated with the load histories and the estimation of future loads require field inspection as a necessary tool for fatigue damage detection and prevention. The fatigue damage condition and fatigue crack growth in bridge components are then assessed with data and information collected from regular field inspection. Inspection may involve the visual examination of structural components and/or the use of a variety of nondestructive evaluation (NDE) techniques, such as dynamic testing method, radiographic inspection method, electric inspection method, sonic and ultrasonic method, acoustic emission method, and dye penetration method [8]. They are conducted typically after observing deterioration and damage such as fatigue cracking in local areas and often expensive, time-consuming, and labor intensive to execute on large-scale bridges. When visual inspections without NDE techniques are used, the effectiveness of the inspection program primarily depends on the inspector's experience and the type of damage observed in generic classes of structures inspected. In cases where NDE techniques are used, the effectiveness of the inspection process, to a great extent, depends on the reliability of the selected technique in fatigue damage detection. These tests may reveal a snapshot of the operating loads and the corresponding responses of the bridge to assess the fatigue life at fatigue-sensitive (especially at fracture-critical) details. However, some of the tests will restrict normal operation of bridges.

Recently, long-term structural health monitoring (SHM) of bridges has been one of the major interests for researchers and engineers in civil, mechanical, material, and computer science fields [9]. Design and implementation of such a system are an integration of analytical skills and instrumentation technologies with the knowledge and experience in bridge design, construction, inspection, maintenance, and management. On-line SHM system is able to provide reliable information pertaining to the integrity, durability, and reliability of bridges. The information can then be incorporated into bridge management and maintenance system (BMMS) for optimizing the maintenance actions and to improve design standards, specifications, codes, and guidelines. SHM is, in fact, an augment but not a substitute of current practice in bridge maintenance and management, not only through the use of advanced technologies in sensing, data acquisition, computing, communication, and data and information management, but also through effective integration of these technologies into an intelligent system. An accurate estimation of the actual situation in fatigue and remaining life of the critical components is an important task of the SHM system, which can be achieved by use of the continuously measured data of dynamic strain from the long-term SHM system.

Fatigue performance of steel bridges depends on a number of factors such as material characteristics, stress history, and environment, and all these factors exhibit uncertainty and randomness during the service life of the bridge. On the other hand, when the field measurement data are used for fatigue condition assessment, the uncertainties related to the field-measured data and the inaccuracies due to data processing techniques are subsistent and hardly avoidable. In view of these facts, it is more appropriate to conduct fatigue life assessment in a probabilistic way than deterministic procedures.

\section{Basic Aspects of Fatigue}

As a well-known phenomenon in metallic structures, fatigue failures in service were already observed in the 19th century. The word "fatigue" was introduced in the 1840s and 1850s to describe failures occurring from repeated loads. The first noteworthy investigation on fatigue is generally dated from the engineering research work of August Wöhler, a technologist in the German railroad system in the early 1850 s. Wöhler was concerned with the failure of railroad axles after various times in service at loads considerably less than the static strength of the structures and undertook the first systematic study of fatigue by performing many laboratory fatigue tests under cyclic stresses. However, in the 19th century, fatigue was thought to be a mysterious phenomenon in the material of an engineering structure because fatigue damage could not be seen and failure apparently occurred without any early warning. In the 20th century, it has been observed that repeated load applications can start a fatigue mechanism in the engineering material leading to nucleation of a microcrack, crack growth, and ultimately to complete failure of a structure.

The history of fatigue covering a time span from 1837 to 1994 was reviewed in a survey paper by Schütz [10]. Mann [11] compiled 21,075 literature sources about fatigue problems on engineering materials, components, and structures covering the period from 1838 to 1990 in four books with an index on subjects, authors, and years. A comprehensive survey of the historical development of the contributions to fatigue on metallic materials, nonmetallic materials, and composites can also be found in Suresh [12]. Cui [13] carried out a state-ofthe-art review of metal fatigue with particular emphasis on the latest developments in fatigue life prediction methods.

2.1. Significance of Fatigue. Fatigue is one of the main causes involved in fatal mechanical failures of a wide range of structures and infrastructures, such as aircrafts, ships, vehicles, offshore structures, pipelines, machinery, pressure vessels, 
cranes, power turbines, transmission towers, bridges, or other engineering structures of high visibility. Such devastating events occur suddenly and result in heavy losses of life and property. Even though no exact percentage is available on the mechanical failures due to fatigue, many studies have suggested that 50 to 90 percent of all mechanical failures are fatigue failures [14]. American Society of Civil Engineers (ASCE) Committee on Fatigue and Fracture Reliability stated that about 80 to 90 percent of failures in metallic structures are related to fatigue fracture [15-18].

The fact that most mechanical failures are associated with fatigue is also testified by the results of an extensive study reported in 1983 by Battelle Columbus Laboratories in conjunction with the National Bureau of Standards (currently NIST, National Institute of Standards and Technology) [19]. It is reported that 141 out of the 230 failures (nearly 61\%) were associated with fatigue and three main causes of fatigue are improper maintenance, fabrication defects, and design deficiencies. The investigation also emphasized that the cost of fatigue-induced fracture could be dramatically reduced by using proper fatigue analysis methods and technologies. However, fatigue failure of metal materials, components, and structures is very recondite and not well understood, nor readily predicted, by designers and engineers due to the complex nature of the fatigue mechanism.

2.2. Mechanism of Metal Fatigue. The mechanism of the fatigue process is quite complicated and controversial which is still only partially understood. However, understanding the fatigue mechanism is a prerequisite for considering various factors which affect fatigue life and fatigue crack growth, such as the material surface quality, residual stress, and environmental influence. This knowledge is essential for the analysis of fatigue properties of an engineering structure. Generally, fatigue is understood as a crack initiation process followed by a crack growth period. Fatigue cracks caused by the repeated application of loads, which individually would be too small to cause failure, usually start from the surface of a structural component where fatigue damage initiates as microscopic shear cracks on crystallographic slip planes as intrusions and extrusions, which is the first stage called crack initiation (stage I). The crack may then propagate from the localized plastic deformation to a macroscopic size in a direction perpendicular to the applied load, which is a crack propagation process (stage II). Finally the crack becomes unstable and the component may fracture. Usually, it is difficult to make an exact description and distinction of the transition between two phases of the fatigue process since this distinction depends upon many factors, such as component size, material, and the methods used to detect cracks.

Typically, the crack initiation period accounts for most of the fatigue life of a component made of steels, particularly in the high-cycle fatigue (HCF) regime (approximately larger than 10,000 cycles). In the low-cycle fatigue (LCF) regime (approximately less than 10,000 cycles), most of the fatigue life is spent on crack propagation. Modern fatigue theories provide separate analyses for each phase of the fatigue process. Crack initiation theories are based on the assumption that fatigue cracks are initiated by the local strains and stresses concentrating on the surface of a structural component due to geometric shapes such as holes, discontinuities, and fillet radii. Crack propagation and final failure stages are analyzed by relating crack growth to the stresses in the component using fracture mechanics.

\section{Classical Fatigue Analysis Methods}

Historically, two overriding considerations have promoted the development of fatigue analysis methods. The first has been the need to provide designers and engineers with methods that are practical, easily implemented, and cost effective. The second consideration has been the need to reconcile these analytical approaches with physical observations. One of the most important physical observations is that the fatigue process can generally be broken into two distinct phases: initiation life and propagation life. This paper introduces three fatigue analysis methods including stress-life $(S-N)$ method, the fracture mechanics approach, and strain-life $(\epsilon-N)$ method. These methods have their own region of application with some degree of overlap among them.

3.1. Fatigue Analysis Using Stress-Life Method. Stress-life method is suited for HCF and mainly used for long fatigue life prediction where stresses and strains are elastic. It does not distinguish between crack initiation and propagation but deals with a total life or the life to failure of a structural component. Stress-life method represents a relationship between the stress range and fatigue failure in the form of $S-N$ curves, attained by cycling test specimens at constantamplitude stresses until visible cracking occurs. Such tests are repeated several times at different stress levels to establish the $S-N$ curves. Running fatigue tests is an expensive and timeconsuming process and curve fitting of fatigue data is also time-consuming. Fatigue analytical models can link theoretical ideas with the observed data to provide a good prediction of future observations. Wöhler was the pioneer researcher who tried to quantify the fatigue strength in accordance with the experimental results of the metal endurance and investigated the fatigue failure in railroad axles for German Railway Industry. His work also led to the characterization of fatigue behavior as the applied stress versus the cycles to failure and to the concept of fatigue limit [20].

Basquin [21] represented the finite life region of the Wöhler curve as $\log N$ on the abscissa and $\log S$ on the ordinate. The Basquin function can be expressed mathematically by

$$
N S^{m}=A
$$

or

$$
\log N=-m \log S+\log A,
$$

where $m$ and $A$ are positive empirical material constants. Obviously, $\log A$ and $m$ are the intercept on the $\log N$ axis and the constant slope of (2), respectively.

Considering the existence of fatigue limit, Stromeyer [22] modified (2) by introducing an extra parameter $F_{l}$ as

$$
\log N=-m \log \left(S-F_{l}\right)+\log A .
$$


In cases where the optimum value of the parameter $F_{l}$ is negative or insignificant, it should be omitted since $F_{l}$ represents the fatigue limit stress.

To show the effect of stress ratio $R_{s}$ or mean stress $S_{m}$ on the fatigue life, Walker [23] proposed the equivalent stress $S_{q}$ model which is given by

$$
\log N=-m \log \left(S_{q}-F_{l}\right)+\log A,
$$

where

$$
S_{q}=S\left(1-R_{s}\right)^{C}
$$

Consider

$$
S_{m}=\frac{S}{2}\left(1+R_{s}\right)
$$

Substituting $R_{s}$ in (5) with $S_{m}$, then

$$
S_{q}=S\left(2-\frac{2 S_{m}}{S}\right)^{C},
$$

where $C$ is a constant parameter.

The stress-life methods usually can be divided into different categories depending on the stress analysis of the structural details, mainly including nominal stress method, hot spot stress method, and effective notch stress method $[24,25]$.

3.1.1. Nominal Stress Method. As a common method for estimating the fatigue life of steel bridges, the nominal stress method has been widely used in most existent codes and standards [3-5]. This method is based on a global consideration focusing on the average stress in the studied cross section according to the fundamental theory of structural mechanics. It is noted that the nominal stress is calculated disregarding the local stress but involving the relative large stress of macrogeometric shape of studied component in the vicinity of welded joints. The nominal stress can be determined using linear elastic structural mechanics for simple structural components or finite element method for relatively complicated structures. Also, the nominal stress can be measured by use of strain gauges which are deployed outside the stress concentration field of the welded joints.

In each code or standard, a variety of $S$ - $N$ curves relevant to specific structural details and loading conditions are of great importance and necessity for fatigue life assessment of steel bridges by use of the nominal stress method. However, the nominal stress method is not suitable for the structural joint if the object detail is extraordinary complicated and incomparable to any classified joints, or the loadings are complex to make it difficult or impossible to determine the nominal stress [26]. Moreover, it has an obvious drawback in that it largely ignores the actual dimensional variations of a specific structural detail [27]. Therefore, as to some structural components of steel bridges, the fatigue life predicted by use of the nominal stress may be unreliable.

3.1.2. Hot Spot Stress Method. An alternative method for fatigue analysis of complicated welded joints is the hot spot stress method which is more reasonable and accurate than the nominal stress method. The International Institute of Welding (IIW) provides comprehensive rules and explicit recommendations in computation of the hot spot stress involving the detailed process of experiments and modeling. Steel bridges are usually composed of lots of longitudinal and transverse plate-type structural members with welded joints at their intersections, for example, joints of main girders and floor beams, floor beams and stringers in plate girder bridges, and longitudinal ribs and transverse ribs in steel deck plates. Investigations on the fatigue behavior of welded joints as well as fundamentals of fatigue strength assessment together with design rules and applications are numerous [28-31]. The welded joints contain some form of geometrical or microstructural discontinuities, and the weld toes in welded joints are the positions with the maximum local stresses where fatigue cracks are most likely to occur. The hot spot stress is the value of the structural stress at the hot spot usually located at a weld toe, which can be calculated by multiplying the nominal stress by a stress concentration factor (SCF) commonly obtained from the finite element analysis or experimental measurements using strain gauges or experiential formulae [32].

Numerical analyses have the distinct advantage of giving the exact positions, directions, and magnitudes of high stresses and the patterns of stress distribution in the entire zone of the specific joint being considered. When using the finite element method to analyze the SCF, the structural behavior can be analyzed by a global finite element model (FEM). A part of the structure including the studied detail, that is large enough to prevent boundary interaction on stress distribution at the welded joint with adequate boundary conditions, is extracted for a more detailed analysis. This selected area should be newly modeled, in which the meshing is refined to obtain enough fine meshes at the welded connection provided with the boundary conditions from the global FEM calculation. The local stress concentration at the weld toe is heavily dependent, in physical models, on the local weld profile and, in numerical analysis, on the mesh refinement [33]. Therefore, it is necessary to find a compromise between the refinement of the meshing and the size in degrees of freedom of the numerical model.

When tests are performed and strain measurements are used to determine the SCF, an elaborate and reasonable instrumentation scheme of strain gauges is crucial [34]. The selection of hot spot locations for instrumentation with strain gauges is improved and refined based on experiences from a number of finite element analyses of the typical details such as rib-to-diaphragm, rib-to-bulkhead, rib-to-stiffener, and diaphragm-to-deck connections [35-40]. The hot spot stress is calculated by extrapolation or regression of stress distribution outside of the weld to the weld toe. For example, Puthli et al. [41] investigated strain/stress concentration factors numerically and experimentally on $\mathrm{X}, \mathrm{T}$, and $\mathrm{K}$ joints using square hollow steel sections and obtained parametric strain/stress concentration factor formulae using regression analyses. Fung et al. [42] studied the SCFs of double plate reinforced tubular T-joints subjected to various types of basic loadings such as axial tension, axial compression, and in-plane and 
out-of-plane bending by using numerical and experimental methods. Other investigations can also be found in Iida [43], Karamanos et al. [44], Gho et al. [45], and Gao et al. [46].

The IIW recommendations for determining the structural hot spot stress are based on the principle of surface extrapolation. Niemi [47] and Niemi et al. [48] gave detailed recommendations concerning stress determination for the fatigue analysis of welded components and proposed distances of 0.4 and 1 times plate thickness $T$ from the weld toe and also distances of 0.5 and 1 times plate thickness for coarser meshes. Yagi et al. [49] proposed a definition of hot spot stress for fatigue design of plate-type structures, and the hot spot stress should be obtained by means of the linear extrapolation of the specific two points at $1.57 \sqrt[4]{T^{3}}$ and $4.9 \sqrt[4]{T^{3}}$ to the weld toe. Nonlinear extrapolation instead of the linear extrapolation is occasionally applied by considering that the structural stress increase in front of the welded joint occurs with various gradients and nonlinearities [50].

Another method for determining structural hot spot stress is through thickness-at-weld-toe method. Radaj [25] demonstrated that structural hot spot stress could be evaluated either by surface extrapolation or by linearization through the pate thickness. Dong [51] proposed an alternative structural hot spot stress computation method combining the features of the surface extrapolation methods with those of the through thickness methods. Doerk et al. [52] explained and compared various procedures for evaluating structural hot spot stress at different types of welded joints. Poutiainen et al. [27] investigated the limits and accuracy of different methods for hot spot stress determination and compared them with finite element analysis results from simple 2D and precise 3D models. Xiao and Yamada [26] proposed a new method of determining structural hot spot stress in welded constructions based on the computed stress $1 \mathrm{~mm}$ below the surface in the direction corresponding to the expected crack path.

Analysis and assessment of the hot spot stress with respect to fatigue have had a rather long history. Pioneering investigations were made in the 1960 s by several researchers to relate the fatigue strength to the local stress measured at a certain point close to the weld toe [53]. In 1970s, the development of the hot spot stress method with the definition of reference points for stress evaluation and extrapolation at certain distances away from the weld toe was reviewed by van Wingerde et al. [50], which was particularly successful for fatigue strength assessment of tubular joints. First attempts to apply the approach to welded joints at plates were seen in the early 1980s, and CEN [5] extended the hot spot stress method to plate-type structures due to the increasing demand although only limited guidance was provided [27]. Up to now, the hot spot stress method has been well accepted and recommended by several national and international codes and standards [5, 54-58].

Little research has been performed on the application of the hot spot stress method to fatigue damage evaluation of the welded plate joint of steel structures, especially for cable-supported steel bridge fatigue evaluation [59]. Miki and Tateishi [60] studied the fatigue strength and local stress for cope hole details existing in I-section beams by fatigue tests, stress measurements, and stress analyses and proposed a simple equation for estimation of SCF based on the results of finite element analysis which was verified by experimental results and confirmed to be accurate. Savaidis and Vormwald [61] investigated numerically and experimentally the hot spot stress and fatigue life of four different welded joints from the floor structure of city buses under bending and tensional cyclic loadings. Han and Shin [62] derived a consistent and unified $S-N$ curve by using the hot spot stress method through a numerical and experimental analysis which can be applied for fatigue strength estimation and fatigue design for general welded steel structures. Chan et al. [59, 63] reported that the hot spot stress method gave a more appropriate fatigue life prediction than the nominal stress method for a steel suspension bridge.

3.1.3. Effective Notch Stress Method. In contrast to the nominal stress method and the hot spot stress method, the effective notch stress method focuses on initiation life prediction for a crack at the root of a notch. This method was proposed by Radaj et al. [53, 64] who were concerned with crack initiation and early growth phase on high-cycle regime using Neuber rule with a fictitious radius of $1 \mathrm{~mm}$ for plate thicknesses of $5 \mathrm{~mm}$ and above. Zhang and Richter [65] developed a new approach by considering the relationship between the stress intensity factor and the notch stress for numerical fatigue life prediction of spot welded structures using a fictitious radius of $0.05 \mathrm{~mm}$. Sonsino et al. [66] investigated the applicability of four examples from different industrial sectors in terms of notch stress concept with the reference radius of $1 \mathrm{~mm}$ for thick walled and $0.05 \mathrm{~mm}$ for thin walled welded steel connections. Aygül et al. [67] conducted a comparative study on five selected welded joints frequently used in steel bridges to investigate the accuracy of three different stress-life methods, that is, nominal stress method, hot spot stress method, and effective notch stress method, and the results revealed that the effective notch stress method, despite its more efforts for both modeling and computation, provides an inconspicuous improvement in estimation of the fatigue strength.

3.2. Fatigue Analysis Using Fracture Mechanics Approach. The fracture mechanics approach is usually applied to predict the propagation life from an initial crack or defect. The method of linear elastic fracture mechanics (LEFM) relates the growth of an initial crack of size $a$ to the number of fatigue cycles, $N$. The fatigue crack growth is generally described by Paris's rule which is expressed by Paris and Erdogan [68]

$$
\frac{d a}{d N}=C(\Delta K)^{m}
$$

where $C$ and $m$ are material-related parameters and the range of stress intensity factor $\Delta K$ can be determined by Broek [69]

$$
\Delta K=S Y(a) \sqrt{\pi a}
$$

where $Y(a)$ is a function of the crack geometry and $S$ is the stress range. 
Many investigations have been performed on bridge fatigue condition assessment using fracture mechanics approach. Fisher [70] illustrated more than twenty-five case studies on fatigue crack phenomena in steel bridges using facture mechanics approach and other theories. Agerskov and Nielsen [71] carried out an investigation on fatigue damage accumulation of steel bridges under random loadings and determined the fatigue life of welded joints in steel highway bridges by a fracture mechanics analysis. Applying a LEFM model to predict crack growth, MacDougall et al. [72] quantified the differences in fatigue life of a short-span and a medium-span bridge under successive passages of either a steel-sprung vehicle or an air-sprung vehicle. Xiao et al. [73] pointed out that lack of penetration zones of $2-3 \mathrm{~mm}$ resulted in low fatigue strength of the butt welded joints with the aid of obtained experimental data of the structural components in Kinuura Bridge and theoretical predictions based on LEFM.

3.3. Fatigue Analysis Using Strain-Life Method. The strainlife method developed in the 1960s is mainly concerned with the crack initiation stage. It is used when the strain is no longer totally elastic but has a plastic component. Short fatigue lives in LCF regime generally occur under these conditions. There have been some investigations on fatigue performance assessment of steel bridges through low-cycle fatigue tests and theoretical strain-life method [74, 75]. Jesus et al. [76] presented crack propagation fatigue data from five Portuguese ancient metallic riveted bridges, and the strainlife fatigue data were correlated using both deterministic and probabilistic models. Up to now, only very limited amount of research has been conducted on fatigue life assessment of steel bridges based on the strain-life method, and the lack of such investigations is mainly because most of the fatigue issues in steel bridges pertain to HCF regime.

3.4. Fatigue Analysis Using Field Measurement Data. When the stress-life method is adopted for bridge fatigue damage evaluation and life prediction, the engineer must have the most realistic and precise load and resistance information to make an accurate fatigue assessment, particularly when the live load stresses are used in cubic equations [77]. In this type of analysis, a small variation in live load stress range will induce drastically different fatigue assessment results. Analysis using computational models of load and structure cannot attempt to mimic the variation in stress range that a typical structural element will experience. Additionally, it would be extremely time-consuming and almost impossible to attempt to account for all of the variables in a conventional simulation analysis. The only way to obtain precise information that accounts for these variables is through the field measurement, where sensors are attached to the bridge elements and the actual stresses and distribution of stresses that the structural element experiences can be measured and recorded. Consequently, it is considered that the fieldmeasured data would provide the simplest and most accurate basis for fatigue assessment. This section provides a comprehensive overview of fatigue analysis of bridge structures based on field-measured data from load-controlled diagnostic load testing and short-term in-service monitoring using NDE techniques and long-term monitoring strategy dominated by SHM technologies.

3.4.1. NDE-Based Fatigue Life Assessment. As the traffic volume and truck weight continue to increase and as bridge conditions continue to deteriorate, a lot of existing steel bridges need to be strengthened, repaired, or reconstructed to insure an acceptable level of safety considering present and future traffic conditions [78]. Furthermore, because of lack of funds and the high cost of reconstruction, NDE technology has been developed to improve the accuracy of bridge condition evaluation [79, 80]. Among the methods, diagnostic load testing with controlled loadings and shortterm in-service monitoring under normal traffic loadings currently are mainly used and the fatigue condition of bridges is then assessed with the obtained data and information from the deployed sensors and data acquisition systems.

The load-controlled diagnostic load testing has the advantages of using known loadings, which allows relatively accurate quantification of the bridge response and the determination of a fairly comprehensive baseline model for a bridge. The limitation to this type of testing, as opposed to inservice monitoring, is that one must use some level of traffic control during testing. The time used for setup is longer, and the response represents only a snapshot in time. The short-term in-service monitoring, on the other hand, has the advantages of not requiring traffic control during monitoring, having a very rapid setup time, and recording the response due to ambient traffic, thereby providing statistical information about actual responses and allowing the response to be tracked over time. The limitation of in-service monitoring is that the weight and the classification of the truck loadings are not specifically known, and the limited data will not allow bridge parameters to be evaluated explicitly [81].

Some investigations on bridge fatigue analysis by use of NDE techniques have been made in recent years. For example, Hahin et al. [82] presented the application of field strain data to condition assessment and prediction of the fatigue life of fifteen highway bridges located in Illinois, and the results were further used to study the significance of truck weight increase and traffic volume growth on the fatigue life of the bridges. DeWolf et al. [83] evaluated the fatigue life for a variety of bridges using field monitoring data by a portable computer-based strain gauge data acquisition system which has been extensively used in Connecticut to assist the Department of Transportation in evaluation and renewal of the state's bridge infrastructure and identified cost-effective maintenance, repair, and replacement strategies [84]. Peil [85] studied the precision on life cycle prediction of steel bridges under live loadings using strain monitoring at the real critical points. Distortion-induced fatigue problems in steel bridges have been investigated by use of the field measurement $[40,86]$.

Chajes and Mertz [87] discussed the diagnostic load tests performed at various stages throughout the process on determining the circumstances leading up to the fatigue crack and its cause and presented the temporary and permanent repair strategies. Zhou [88] proved that the fatigue evaluation based on field-measured stress range histograms under actual traffic 
loads was a more accurate and efficient method for existing bridges and applied this approach in assessing the remaining fatigue life of aged riveted steel bridges. Ermopoulos and Spyrakos [89] identified the structural components in need of strengthening or replacement for a 19th century railway bridge through static and dynamic field measurements as well as laboratory tests and proposed the strengthening schemes and predicted the remaining fatigue life of the bridge in its present condition and after the suggested strengthening. Investigations into fatigue evaluation of steel bridges by use of NDE techniques were also reported by Moses et al. [90], Roeder et al. [91], Abdou et al. [92], Spyrakos et al. [93], Alampalli and Lund [94], and Malm and Andersson [95].

3.4.2. SHM-Based Fatigue Life Assessment. To secure structural and operational safety throughout the bridge life-cycles and issue early warnings on any deterioration or damage of bridges prior to costly repair or even catastrophic collapse, the significance of implementing long-term SHM systems for bridges has been increasingly recognized in USA [96-98], Europe [99-104], Japan [105, 106], Korea [107, 108], Hong Kong $[109,110]$, Chinese mainland [111-116], and Canada [117-119], among others. A review of the literature indicates that there is a growing trend in incorporation of computerand sensor-based long-term health monitoring systems into bridges especially for long-span bridges due to their large investments, their significant roles in economics, and innovative techniques used to design and construct such bridges.

An important function of SHM systems is to monitor structural health and performance, as well as accurately estimating the actual status in fatigue and remaining life of the bridge [120]. It has become an important issue of high research interest with the development of SHM systems for large complicated structures. However, little work on fatigue analysis and condition assessment of bridge structures based on long-term monitoring data has been made in the past decade because SHM is a relatively new technology for applications in civil engineering communities, and even a comprehensive definition of SHM and the system design guidelines have yet to be standardized; another important reason is that such a complicated system has not been extensively installed in most of the bridges worldwide due to high cost.

However, investigations on fatigue condition assessment based on long-term monitoring data still can be found. Li et al. [121] developed a methodology and strategy for fatigue damage analysis and life prediction, and fatigue condition assessment of bridge-deck sections of the Tsing Ma Bridge was carried out taking full advantage of the on-line SHM data. Connor et al. [122] developed and implemented an indepth instrumentation, testing, and monitoring program on the Bronx-Whitestone Bridge as part of a comprehensive fatigue evaluation for the replacement orthotropic bridge deck. $\mathrm{Xu}$ et al. [123] developed a systematic framework for assessing long-term buffeting-induced fatigue damage to a long suspension bridge by integrating a few important wind and structural components with continuum damage mechanicsbased fatigue damage assessment method. Ye et al. [124] presented a study on fatigue life assessment of the Tsing $\mathrm{Ma}$ Bridge using the standard daily stress spectrum method.

\section{Reliability-Based Fatigue Condition Assessment}

In October 1945, a paper entitled "The Safety of Structures" appeared in the Proceedings of the ASCE. This historical paper was written by Freudenthal, and its purpose was to analyze the safety factor in engineering structures in order to establish a rational method of evaluating its magnitude. It was selected for inclusion with many discussions in the 1947 Transactions of the ASCE [125]. The publication of this paper marked the beginning of structural reliability studies in the United States [15]. Over the past several decades, the concepts and methods of structural reliability have developed rapidly and become more widely understood and accepted. There have been a lot of studies and applications [126-132] and comprehensive books [133-139] on reliability-based structure analysis.

Fatigue reliability evaluation is a very important task for the design and management of bridges. For highway and railway bridges, the techniques of fatigue reliability have been applied mainly in Mohammadi and Polepeddi [140] and Lukić and Cremona [141]: (i) condition assessment and estimation of the remaining lifetime of bridges, where probabilistic methods can be used to obtain estimates of the adequacy of the existing structure, need for increased inspection in the future to prevent failure, and approximate remaining fatigue lifetime based on projections of the future loads, and (ii) development of probability-based design stress ranges for fatigue-critical bridge components, where accurate traffic load data can be acquired through weigh-in-motion (WIM) systems, from which an extensive amount of data are available showing distribution of loads by its time of appearance, transversal position, speed, number of axles, gross weight of axles, and distance between axles.

Most of the research work on reliability-based fatigue analysis has focused on steel bridges. A comprehensive literature review on the existing fatigue reliability approaches for reassessment of steel structures, including railway and highway bridges, is available in Byers et al. [142, 143]. The general approach for analyzing reliability against fatigue failure is first to formulate a mathematical model, whether on the basis of mechanics or extensive observations of the phenomenon, which incorporates as many of the variables as practical that are known to affect fatigue behavior. The probabilistic and statistical analysis method then is performed within this provided analytical framework.

\subsection{Fatigue Reliability Assessment Using Stress-Life Method.} Fatigue load and resistance are two main variables when the stress-life method is chosen for developing fatigue reliability analytical models. The fatigue load model should be determined not only by magnitude but also by frequency of occurrence which can be obtained by WIM measurements $[144,145]$, and resistance model should be derived from a lot of fatigue tests under varying amplitude loading [146]. Usually, the log-normal distribution and the Weibull distribution are used for load and strength probability distribution [147151]. Murty et al. [152] proposed a method to deal with the derivation of the fatigue strength distribution as a function 
of number of cycles to failure. Zhao et al. [153] developed an approach to determine an appropriate distribution from four possible assumed distributions of the fatigue life under limited data. Lorén [154] presented a model for calculating the fatigue limit distribution based on the inclusion size.

Research efforts have been devoted by a number of investigators for modeling the stress range data by using various single theoretical probability distributions. Beta distribution has been suggested as a theoretical stress range distribution model to describe the field data by Ang and Munse [155] and Walker [156]. Based on 106 recorded stress range histograms, Yamada and Albrecht [157] presented that the probability distribution of dimensionless stress range normalized by the maximum stress range could be expressed by a polynomial distribution. In order to select a single nondimensional mathematical expression that can be used to represent the stress histogram of highway bridges, a continuous two-parameter Rayleigh curve was used to model the probability distribution of stress range in the fatigue test program [158]. Wirsching [159] assumed that the long-term stress range data were Weibull distributed and Madsen [160] took the nominal stress range as a random variable with normal distribution. Park et al. [161] successfully expressed the stress range frequency distribution of 400 block loadings by a log-normal probability distribution. Ni et al. [162] proposed a method for modeling of the stress spectrum using finite mixture distributions and long-term monitoring data of dynamic strain.

There have been a number of studies on the reliability analysis for fatigue damage and life prediction of bridges [163-171]. Imam et al. [172] presented a probabilistic fatigue assessment methodology for riveted railway bridges and applied this method to a typical, short-span, riveted UK railway bridge under historical and present-day train loading. Kwon and Frangopol [173] performed fatigue reliability assessment of steel bridges using the probability density function of the equivalent stress range obtained by monitoring data. Ni et al. [174] developed a fatigue reliability model for fatigue life and reliability evaluation of steel bridges with long-term monitoring data, which integrates the probability distribution of hot spot stress range with a continuous probabilistic formulation of Miner's damage cumulative rule. Research efforts on probabilistic fatigue life estimation of steel bridges by use of a bilinear $S-N$ approach can be found in Kwon et al. [175] and Soliman et al. [176].

4.2. Fatigue Reliability Assessment Using Fracture Mechanics Approach. A significant number of investigations on fatigue reliability assessment of bridges have been conducted by use of the fracture mechanics approach $[161,163,177]$. Based on field-measured data from nondestructive inspections, Zhao and Haldar [78] proposed a LEFM-based reliability model considering uncertainties in different aspects including initial crack size, crack aspects ratio, material properties, and number of stress cycles. Lukić and Cremona [141] presented a probabilistic assessment procedure of steel components damaged by fatigue using a fracture mechanics-based crack growth model, which was applied to a transverse-stifferto-bottom-flange welded joint of a typical steel bridge. Righiniotis and Chryssanthopoulos [178] conducted an investigation on the application of probabilistic fracture mechanics approach to predict the fatigue life of welded joints with initiation cracks through a bilinear crack growth law. Pipinato et al. [179] applied a LEFM approach in a probabilistic content to evaluate the fatigue reliability of steel bridges in the presence of seismic loading. Wang et al. [180] presented a procedure for assessing and updating the fatigue reliability of existing steel bridge components using nondestructive inspection techniques and Bayes theorem based on the probabilistic fracture mechanics method. Guo and Chen [181] performed an investigation on fatigue reliability assessment of welded details of a 40-year-old steel box-girder bridge integrating the LEFM approach and field data obtained from the long-term stress monitoring.

\section{Conclusions}

This paper provides a summary of research developments in the area of fatigue life assessment of steel bridges. Based on the overall review of fatigue-relevant theories, methods, technologies, and applications, the following conclusions are made: (i) the nominal stress-life method is widely used for fatigue-related design and evaluation of steel bridges; however, the estimated fatigue life by use of the hot spot stress method has been proved to be more accurate and effective; (ii) field measurement data will provide the most accurate information for derivation of the key physical parameters and their statistical properties in fatigue condition assessment, and therefore it is crucial and desirable to develop data-driven methods for fatigue life assessment of steel bridges; and (iii) in recognition of the uncertainties and randomness inherent in the nature of fatigue phenomenon and measurement data, investigations for probabilistic fatigue life assessment of steel bridges are deemed to be reasonable. By so doing, reliable fatigue condition assessment can be achieved for instrumented steel bridges and rational strategies on bridge inspection and maintenance can be executed in accordance with the correlativity between reliability indices and predefined inspection and/or maintenance actions.

\section{Conflict of Interests}

The authors declare that there is no conflict of interests regarding the publication of this paper.

\section{Acknowledgments}

The work described in this paper was supported by the National Science Foundation of China under Grant nos. 51308493 and U1234204, the Research Fund for the Doctoral Program of Higher Education of China under Grant no. 20130101120080, the Fundamental Research Funds for the Central Universities of China under Grant no. 2013QNA4023, and the Department of Education of Zhejiang Province, China, under Grant no. Y201328906.

\section{References}

[1] M. A. Miner, "Cumulative damage in fatigue," Journal of Applied Mechanics, vol. 12, no. 3, pp. 159-164, 1945. 
[2] M. K. Chryssanthopoulos and T. D. Righiniotis, "Fatigue reliability of welded steel structures," Journal of Constructional Steel Research, vol. 62, no. 11, pp. 1199-1209, 2006.

[3] BSI, BS 5400: Steel, Concrete and Composite Bridges-Part 10: Code of Practice for Fatigue, British Standards Institution, London, UK, 1980.

[4] AASHTO, Guide Specifications for Fatigue Evaluation of Existing Steel Bridges, American Association of State Highway and Transportation Officials, Washington, DC, USA, 1990.

[5] CEN, Eurocode 3: Design of Steel Structures, Part 1-9: Fatigue, European Committee for Standardization, Brussels, Belgium, 1992.

[6] M. Matsuishi and T. Endo, "Fatigue of metals subjected to varying stress," Japan Society of Mechanical Engineers, pp. 37-40, 1968.

[7] S. D. Downing and D. F. Socie, "Simple rainflow counting algorithms," International Journal of Fatigue, vol. 4, no. 1, pp. 31-40, 1982.

[8] J. D. Achenbach, "Quantitative nondestructive evaluation," International Journal of Solids and Structures, vol. 37, no. 1-2, pp. 13-27, 2000.

[9] D. Balageas, C. P. Fritzen, and A. Guemes, Structural Health Monitoring, Wiley-ISTE, London, UK, 2006.

[10] W. Schütz, "A history of fatigue," Engineering Fracture Mechanics, vol. 54, no. 2, pp. 263-300, 1996.

[11] J. Y. Mann, Bibliography on the Fatigue of Materials, Components and Structures, vol. 1-4, Pergamon Press, Oxford, UK, 1990.

[12] S. Suresh, Fatigue of Materials, Cambridge University Press, New York, NY, USA, 1998.

[13] W. Cui, "A state-of-the-art review on fatigue life prediction methods for metal structures," Journal of Marine Science and Technology, vol. 7, no. 1, pp. 43-56, 2002.

[14] R. I. Stephens, A. Fatemi, R. R. Stephens, and H. O. Fuchs, Metal Fatigue in Engineering, John Wiley \& Sons, New York, NY, USA, 2001.

[15] ASCE Committee on Fatigue and Fracture Reliability, "Fatigue reliability: introduction," ASCE Journal of the Structural Division, vol. 108, no. 1, pp. 3-23, 1982.

[16] ASCE Committee on Fatigue and Fracture Reliability, "Fatigue reliability: quality assurance and maintainability," ASCE Journal of the Structural Division, vol. 108, no. 1, pp. 25-46, 1982.

[17] ASCE Committee on Fatigue and Fracture Reliability, "Fatigue reliability: variable amplitude loading," ASCE Journal of the Structural Division, vol. 108, no. 1, pp. 47-69, 1982.

[18] ASCE Committee on Fatigue and Fracture Reliability, "Fatigue reliability: development of criteria for design," ASCE Journal of the Structural Division, vol. 108, no. 1, pp. 71-88, 1982.

[19] R. P. Reed, J. H. Smith, and B. W. Christ, The Economic Effects of Fracture in the United States, vol. 647-1 of National Bureau of Standards Special Publication, U.S. Department of Commerce, Gaithersburg, Md, USA, 1983.

[20] K. S. Al-Rubaie, "A general model for stress-life fatigue prediction," Materialwissenschaft und Werkstofftechnik, vol. 39, no. 6, pp. 400-406, 2008.

[21] O. H. Basquin, "The exponential law of endurance tests," in Proceedings of American Society for Testing and Materials, vol. 10, pp. 625-630, West Conshohocken, Pa, USA, 1910.

[22] C. E. Stromeyer, "The determination of fatigue limits under alternating stress conditions," Proceedings of the Royal Society of London A, vol. 90, no. 620, pp. 411-425, 1914.
[23] E. K. Walker, "The effect of stress ratio during crack propagation and fatigue for 2024-T3 and 7075-T6 aluminum," in Effects of Environment and Complex Load History on Fatigue Life, vol. 462 of ASTM Special Technical Publication,, pp. 1-14, American Society for Testing and Materials, Philadelphia, Pa, USA, 1970.

[24] W. Fricke, "Fatigue analysis of welded joints: state of development," Marine Structures, vol. 16, no. 3, pp. 185-200, 2003.

[25] D. Radaj, "Review of fatigue strength assessment of nonwelded and welded structures based on local parameters," International Journal of Fatigue, vol. 18, no. 3, pp. 153-170, 1996.

[26] Z.-G. Xiao and K. Yamada, "A method of determining geometric stress for fatigue strength evaluation of steel welded joints," International Journal of Fatigue, vol. 26, no. 12, pp. 1277-1293, 2004.

[27] I. Poutiainen, P. Tanskanen, and G. Marquis, "Finite element methods for structural hot spot stress determination-a comparison of procedures," International Journal of Fatigue, vol. 26, no. 11, pp. 1147-1157, 2004.

[28] T. R. Gurney, Fatigue of Welded Structures, Cambridge University Press, Cambridge, UK, 2nd edition, 1979.

[29] D. R. V. van Delft, "Two dimensional analyses of stress at the vicinity of weld toes of tubular structures," Stevin Report 6-818, Stevin Laboratory, Delft University of Technology, Delft, The Netherlands, 1981.

[30] S. J. Maddox, Fatigue Strength of Welded Structures, Abington, Cambridge, UK, 1991.

[31] A. Hobbacher, "Fatigue design of welded joints and components," IIW Document XIII-1539-96/XV-845-96, Abington, Cambridge, UK, 1996.

[32] W. D. Pilkey, Peterson's Stress Concentration Factors, John Wiley \& Sons, New York, NY, USA, 3rd edition, 2008.

[33] M. R. Morgan and M. M. K. Lee, "New parametric equations for stress concentration factors in tubular K-joints under balanced axial loading," International Journal of Fatigue, vol. 19, no. 4, pp. 309-317, 1997.

[34] X. W. Ye, Y. Q. Ni, and J. M. Ko, "Experimental evaluation of stress concentration factor of welded steel bridge T-joints," Journal of Constructional Steel Research, vol. 70, pp. 78-85, 2012.

[35] M. R. Kaczinski, F. E. Stokes, P. Lugger, and J. W. Fisher, "Williamsburg Bridge, orthotropic deck fatigue tests," ATLSS Report No. 97-04, Department of Civil and Environmental Engineering, Lehigh University, Bethlehem, Pa, USA, 1997.

[36] A. S. G. Barth and M. D. Bowman, "Fatigue behavior of welded diaphragm-to-beam connections," ASCE Journal of Structural Engineering, vol. 127, no. 10, pp. 1145-1152, 2001.

[37] P. A. Tsakopoulos and J. W. Fisher, "Fatigue resistance investigation for the orthotropic deck on the Bronx-Whitestone Bridge," ATLSS Report No. 02-05, Department of Civil and Environmental Engineering, Lehigh University, Bethlehem, Pa, USA, 2002.

[38] R. J. Connor, "Influence of cutout geometry on stresses at welded rib-to-diaphragm connections in steel orthotropic bridge decks," Transportation Research Record, vol. 1892, pp. 7887, 2004.

[39] M. Al-Emrani, "Fatigue performance of stringer-to-floor-beam connections in riveted railway bridges," ASCE Journal of Bridge Engineering, vol. 10, no. 2, pp. 179-185, 2005.

[40] R. J. Connor and J. W. Fisher, "Identifying effective and ineffective retrofits for distortion fatigue cracking in steel bridges using field instrumentation," ASCE Journal of Bridge Engineering, vol. 11, no. 6, pp. 745-752, 2006. 
[41] R. S. Puthli, J. Wardenier, C. H. M. de Koning, A. M. van Wingerde, and F. J. van Dooren, "Numerical and experimental determination of strain (stress) concentration factors of welded joints between square hollow sections," Heron, vol. 33, no. 2, pp. 1-50, 1988.

[42] T. C. Fung, C. K. Soh, T. K. Chan, and E. Erni, "Stress concentration factors of doubler plate reinforced tubular T joints," ASCE Journal of Structural Engineering, vol. 128, no. 11, pp. 13991412, 2002.

[43] K. Iida, "Application of the hot spot strain concept to fatigue life prediction," Welding in the World, vol. 22, no. 9-10, pp. 222-247, 1984.

[44] S. A. Karamanos, A. Romeijn, and J. Wardenier, "Stress concentrations in tubular DT-joints for fatigue design," ASCE Journal of Structural Engineering, vol. 126, no. 11, pp. 1320-1330, 2000.

[45] W. M. Gho, T. C. Fung, and C. K. Soh, "Stress and strain concentration factors of completely overlapped tubular $\mathrm{K}(\mathrm{N})$ joints," ASCE Journal of Structural Engineering, vol. 129, no. 1, pp. 21-29, 2003.

[46] F. Gao, Y. B. Shao, and W. M. Gho, "Stress and strain concentration factors of completely overlapped tubular joints under lap brace IPB load," Journal of Constructional Steel Research, vol. 63, no. 3, pp. 305-316, 2007.

[47] E. Niemi, Stress Determination for Fatigue Analysis of Welded Components: IIS/IIW-1221-93, Abington, Cambridge, UK, 1995.

[48] E. Niemi, W. Fricke, and S. J. Maddox, "Structural hot-spot stress approach to fatigue analysis of welded components," IIW Document, XIII-1819-00/XV-1090-01/ XIII-WG3-06-99, International Institute of Welding, Villeurbanne, France, 2003.

[49] J. Yagi, S. Machida, Y. Tomita, M. Matoba, and T. Kawasaki, "Definition of hot spot stress in welded plate type structure for fatigue assessment," IIW Document XIII-1414-91, International Institute of Welding, Villeurbanne, France, 1991.

[50] A. M. van Wingerde, J. A. Packer, and J. Wardenier, "Criteria for the fatigue assessment of hollow structural section connections," Journal of Constructional Steel Research, vol. 35, no. 1, pp. 71-115, 1995.

[51] P. Dong, "A structural stress definition and numerical implementation for fatigue analysis of welded joints," International Journal of Fatigue, vol. 23, no. 10, pp. 865-876, 2001.

[52] O. Doerk, W. Fricke, and C. Weissenborn, "Comparison of different calculation methods for structural stresses at welded joints," International Journal of Fatigue, vol. 25, no. 5, pp. 359369, 2003.

[53] D. Radaj, C. M. Sonsino, and W. Fricke, Fatigue Assessment of Welded Joints by Local Approaches, Abington, Cambridge, UK, 2nd edition, 2006.

[54] ECCS, Recommendations for the Fatigue Design of Steel Structures, European Convention for Constructional Steelwork, Brussels, Belgium, 1985.

[55] API, "Recommended practice for planning, designing, and constructing fixed offshore platforms," APIRP2A-LRFD, American Petroleum Institute, Washington, DC, USA, 1993.

[56] BSI, BS 7608: Code of Practice for Fatigue Design and Assessment of Steel Structures, British Standards Institution, London, UK, 1993.

[57] AWS, Structural Welding Code: Steel: ANSI/AWS D1.1 98, American Welding Society, Miami, Fla, USA, 1998.

[58] IIW, "Fatigue design procedures for welded hollow section joints," IIW Document XIII-1804-99/XV-1035-99, Recommendations for IIW Subcommision XV-E, Abington, Cambridge, UK, 2000.
[59] T. H. T. Chan, T. Q. Zhou, Z. X. Li, and L. Guo, "Hot spot stress approach for Tsing Ma Bridge fatigue evaluation under traffic using finite element method," Structural Engineering and Mechanics, vol. 19, no. 3, pp. 261-279, 2005.

[60] C. Miki and K. Tateishi, "Fatigue strength of cope hole details in steel bridges," International Journal of Fatigue, vol. 19, no. 6, pp. 445-455, 1997.

[61] G. Savaidis and M. Vormwald, "Hot-spot stress evaluation of fatigue in welded structural connections supported by finite element analysis," International Journal of Fatigue, vol. 22, no. 2, pp. 85-91, 2000.

[62] S. Han and B. Shin, "Use of hot spot stress for estimating the fatigue strength of welded components," Steel Research, vol. 71, no. 11, pp. 466-473, 2000.

[63] T. H. T. Chan, L. Guo, and Z. X. Li, "Finite element modelling for fatigue stress analysis of large suspension bridges," Journal of Sound and Vibration, vol. 261, no. 3, pp. 443-464, 2003.

[64] D. Radaj, Design and Analysis of Fatigue Resistant Welded Structures, Abington, Cambridge, UK, 1990.

[65] G. Zhang and B. Richter, "New approach to the numerical fatigue-life prediction of spot-welded structures," Fatigue \& Fracture of Engineering Materials \& Structures, vol. 23, no. 6, pp. 499-508, 2000.

[66] C. M. Sonsino, W. Fricke, F. De Bruyne, A. Hoppe, A. Ahmadi, and G. Zhang, "Notch stress concepts for the fatigue assessment of welded joints-background and applications," International Journal of Fatigue, vol. 34, no. 1, pp. 2-16, 2012.

[67] M. Aygül, M. Bokesj, M. Heshmati, and M. Mohammad, "A comparative study of different fatigue failure assessments of welded bridge details," International Journal of Fatigue, vol. 49, pp. 62-72, 2013.

[68] P. C. Paris and F. Erdogan, "A critical analysis of crack propagation laws," Journal of Basic Engineering, vol. 85, no. 4, pp. 528534, 1963.

[69] D. Broek, Elementary Engineering Fracture Mechanics, Martinus Nijhoff, Dordrecht, The Netherlands, 4th edition, 1986.

[70] J. W. Fisher, Fatigue and Fracture in Steel Bridges: Case Studies, John Wiley \& Sons, New York, NY, USA, 1984.

[71] H. Agerskov and J. A. Nielsen, "Fatigue in steel highway bridges under random loading," ASCE Journal of Structural Engineering, vol. 125, no. 2, pp. 152-162, 1999.

[72] C. MacDougall, M. F. Green, and S. Shillinglaw, "Fatigue damage of steel bridges due to dynamic vehicle loads," ASCE Journal of Bridge Engineering, vol. 11, no. 3, pp. 320-328, 2006.

[73] Z.-G. Xiao, K. Yamada, J. Inoue, and K. Yamaguchi, "Fatigue cracks in longitudinal ribs of steel orthotropic deck," International Journal of Fatigue, vol. 28, no. 4, pp. 409-416, 2006.

[74] M. Sakano and M. A. Wahab, "Extremely low cycle (ELC) fatigue cracking behaviour in steel bridge rigid frame piers," Journal of Materials Processing Technology, vol. 118, no. 1-3, pp. 36-39, 2001.

[75] H. B. Ge, L. Kang, and Y. Tsumura, "Extremely low-cycle fatigue tests of thick-walled steel bridge piers," ASCE Journal of Bridge Engineering, vol. 18, no. 9, pp. 858-870, 2013.

[76] A. M. P. D. Jesus, A. L. L. da Silva, M. V. Figueiredo, J. A. F. O. Correia, A. S. Ribeiro, and A. A. Fernandes, "Strain-life and crack propagation fatigue data from several Portuguese old metallic riveted bridges," Engineering Failure Analysis, vol. 18, no. 1, pp. 148-163, 2011.

[77] R. R. Sartor, M. P. Culmo, and J. T. DeWolf, "Short-term strain monitoring of bridge structures," ASCE Journal of Bridge Engineering, vol. 4, no. 3, pp. 157-164, 1999. 
[78] Z. Zhao and A. Haldar, "Bridge fatigue damage evaluation and updating using non-destructive inspections," Engineering Fracture Mechanics, vol. 53, no. 5, pp. 775-788, 1996.

[79] F. M. Russo, T. J. Wipf, and F. W. Klaiber, "Diagnostic load tests of a prestressed concrete bridge damaged by overheight vehicle impact," Transportation Research Record, vol. 1696, pp. 103-110, 2000.

[80] H. W. Shenton III, M. J. Chajes, B. Sivakumar, and W. W. Finch, "Field tests and in-service monitoring of Newburgh-Beacon Bridge," Transportation Research Record, vol. 1845, pp. 163-170, 2003.

[81] M. J. Chajes, H. W. Shenton, and D. O'Shea, "Bridge-condition assessment and load rating using nondestructive evaluation methods," Transportation Research Record, vol. 1696, pp. 83-91, 2000.

[82] C. Hahin, J. M. South, J. Mohammadi, and R. K. Polepeddi, "Accurate and rapid determination of fatigue damage in steel bridges," ASCE Journal of Structural Engineering, vol. 119, no. 1, pp. 150-168, 1993.

[83] J. T. DeWolf, R. G. Lauzon, and M. P. Culmo, "Monitoring bridge performance," Structural Health Monitoring, vol. 1, no. 2, pp. 129-138, 2002.

[84] S. Chakraborty and J. T. Dewolf, "Development and implementation of a continuous strain monitoring system on a multi-girder composite steel bridge," ASCE Journal of Bridge Engineering, vol. 11, no. 6, pp. 753-762, 2006.

[85] U. Peil, "Assessment of bridges via monitoring," Structure and Infrastructure Engineering, vol. 1, no. 2, pp. 101-117, 2005.

[86] Y. Shifferaw and F. S. Fanous, "Field testing and finite element analysis of steel bridge retrofits for distortion-induced fatigue," Engineering Structures, vol. 49, pp. 385-395, 2013.

[87] M. J. Chajes and D. R. Mertz, "Fracture analysis and retrofit design for the I-95 bridge over the Brandywine River," in Recent Developments in Bridge Engineering, K. M. Mahmoud, Ed., pp. 205-220, Balkema, Lisse, The Netherlands, 2003.

[88] Y. E. Zhou, "Assessment of bridge remaining fatigue life through field strain measurement," ASCE Journal of Bridge Engineering, vol. 11, no. 6, pp. 737-744, 2006.

[89] J. Ermopoulos and C. C. Spyrakos, "Validated analysis and strengthening of a 19th century railway bridge," Engineering Structures, vol. 28, no. 5, pp. 783-792, 2006.

[90] F. Moses, J. P. Lebet, and R. Bez, "Applications of field testing to bridge evaluation," ASCE Journal of Structural Engineering, vol. 120, no. 6, pp. 1745-1762, 1994.

[91] C. W. Roeder, G. MacRae, P. Crocker, K. Arima, and S. Wong, "Dynamic response and fatigue of steel tied-arch bridge," ASCE Journal of Bridge Engineering, vol. 5, no. 1, pp. 14-21, 2000.

[92] S. Abdou, W. Zhang, and J. W. Fisher, "Orthotropic deck fatigue investigation at Triborough Bridge," Transportation Research Record, vol. 1845, pp. 153-162, 2003.

[93] C. C. Spyrakos, I. G. Raftoyiannis, and J. C. Ermopoulos, "Condition assessment and retrofit of a historic steel-truss railway bridge," Journal of Constructional Steel Research, vol. 60, no. 8, pp. 1213-1225, 2004.

[94] S. Alampalli and R. Lund, "Estimating fatigue life of bridge components using measured strains," ASCE Journal of Bridge Engineering, vol. 11, no. 6, pp. 725-736, 2006.

[95] R. Malm and A. Andersson, "Field testing and simulation of dynamic properties of a tied arch railway bridge," Engineering Structures, vol. 28, no. 1, pp. 143-152, 2006.
[96] D. J. Pines and A. E. Aktan, "Status of structural health monitoring of long-span bridges in the United States," Progress in Structural Engineering and Materials, vol. 4, no. 4, pp. 372-380, 2002.

[97] P. C. Chang, A. Flatau, and S. C. Liu, "Review paper: health monitoring of civil infrastructure," Structural Health Monitoring, vol. 2, no. 3, pp. 257-267, 2003.

[98] M. Q. Feng, "Application of structural health monitoring in civil infrastructure," Smart Structures and Systems, vol. 5, no. 4, pp. 469-482, 2009.

[99] F. Casciati, "An overview of structural health monitoring expertise within the European Union," in Structural Health Monitoring and Intelligent Infrastructure, Z. S. Wu and M. Abe, Eds., pp. 31-37, Balkema, Lisse, The Netherlands, 2003.

[100] J. M. W. Brownjohn, "Structural health monitoring of civil infrastructure," Philosophical Transactions of the Royal Society A, vol. 365, no. 1851, pp. 589-622, 2007.

[101] J. C. Matos, O. Garcia, A. A. Henriques, J. R. Casas, and J. Vehi, "Health monitoring system (HMS) for structural assessment," Smart Structures and Systems, vol. 5, no. 3, pp. 223-240, 2009.

[102] F. Moschas and S. Stiros, "Measurement of the dynamic displacements and of the modal frequencies of a short-span pedestrian bridge using GPS and an accelerometer," Engineering Structures, vol. 33, no. 1, pp. 10-17, 2011.

[103] P. A. Psimoulis and S. C. Stiros, "Measuring deflections of a short-span railway bridge using a Robotic Total Station," ASCE Journal of Bridge Engineering, vol. 18, no. 2, pp. 182-185, 2013.

[104] F. Moschas and S. C. Stiros, "Three-dimensional dynamic deflections and natural frequencies of a stiff footbridge based on measurements of collocated sensors," Structural Control and Health Monitoring, vol. 21, no. 1, pp. 23-42, 2014.

[105] A. Mita, "Emerging needs in Japan for health monitoring technologies in civil and building structures," in Structural Health Monitoring 2000, F. K. Chang, Ed., pp. 56-68, Technomic, Lancaster, UK, 1999.

[106] Y. Fujino, "Vibration, control and monitoring of long-span bridges-recent research, developments and practice in Japan," Journal of Constructional Steel Research, vol. 58, no. 1, pp. 71-97, 2002.

[107] H. M. Koh, J. F. Cho, S. K. Kim, and C. Y. Kim, "Recent application and development of structural health monitoring systems and intelligent structures in Korea," in Structural Health Monitoring and Intelligent Infrastructure, Z. S. Wu and M. Abe, Eds., pp. 99-111, Balkema, Lisse, The Netherlands, 2003.

[108] C. B. Yun, J. J. Lee, S. K. Kim, and J. W. Kim, "Recent R\&D activities on structural health monitoring for civil infra-structures in Korea," Journal of Civil Engineering, vol. 7, no. 6, pp. 637651, 2003.

[109] J. M. Ko and Y. Q. Ni, “Technology developments in structural health monitoring of large-scale bridges," Engineering Structures, vol. 27, no. 12, pp. 1715-1725, 2005.

[110] K.-Y. Wong, "Design of a structural health monitoring system for long-span bridges," Structure and Infrastructure Engineering, vol. 3, no. 2, pp. 169-185, 2007.

[111] G. Chen and N. Li, "Research on the health monitoring for long span bridge in China," in Proceedings of the International Conference on Electric Technology and Civil Engineering (ICETCE '11), pp. 6814-6816, Hong Kong, China, April 2011.

[112] Q. Zhang and Y. Zhou, "Investigation of the applicability of current bridge health monitoring technology," Structure and Infrastructure Engineering, vol. 3, no. 2, pp. 159-168, 2007. 
[113] J. P. Ou and H. Li, "Structural health monitoring in mainland China: review and future trends," Structural Health Monitoring, vol. 9, no. 3, pp. 219-231, 2010.

[114] T.-H. Yi, H.-N. Li, and M. Gu, "Recent research and applications of GPS-based monitoring technology for high-rise structures," Structural Control and Health Monitoring, vol. 20, no. 5, pp. 649670, 2013.

[115] T. H. Yi, H. N. Li, and M. Gu, "Wavelet based multi-step filtering method for bridge health monitoring using GPS and accelerometer," Smart Structures and Systems, vol. 11, no. 4, pp. 331$348,2013$.

[116] T. H. Yi, H. N. Li, and H. M. Sun, "Multi-stage structural damage diagnosis method based on "energy-damage" theory," Smart Structures and Systems, vol. 12, no. 3-4, pp. 345-361, 2013.

[117] M. S. Cheung, G. S. Tadros, T. Brown, W. H. Dilger, A. Ghali, and D. T. Lau, "Field monitoring and research on performance of the confederation bridge," Canadian Journal of Civil Engineering, vol. 24, no. 6, pp. 951-962, 1997.

[118] A. A. Mufti, "Structural health monitoring of innovative Canadian civil engineering structures," Structural Health Monitoring, vol. 1, no. 1, pp. 89-103, 2002.

[119] S. L. Desjardins, N. A. Londoño, D. T. Lau, and H. Khoo, "Realtime data processing, analysis and visualization for structural monitoring of the confederation bridge," Advances in Structural Engineering, vol. 9, no. 1, pp. 141-157, 2006.

[120] T. H. T. Chan, Z. X. Li, and J. M. Ko, "Fatigue analysis and life prediction of bridges with structural health monitoring datapart II: application," International Journal of Fatigue, vol. 23, no. 1, pp. 55-64, 2001.

[121] Z. X. Li, T. H. T. Chan, and J. M. Ko, "Fatigue analysis and life prediction of bridges with structural health monitoring data-part I: methodology and strategy," International Journal of Fatigue, vol. 23, no. 1, pp. 45-53, 2001.

[122] R. J. Connor, S. O. Richards, and J. W. Fisher, "Long-term remote monitoring of prototype orthotropic deck panels on the Bronx-Whitestone Bridge for fatigue evaluation," in Recent Developments in Bridge Engineering, K. M. Mahmoud, Ed., pp. 257-268, Balkema, Lisse, The Netherlands, 2003.

[123] Y. L. Xu, T. T. Liu, and W. S. Zhang, "Buffeting-induced fatigue damage assessment of a long suspension bridge," International Journal of Fatigue, vol. 31, no. 3, pp. 575-586, 2009.

[124] X. W. Ye, Y. Q. Ni, K. Y. Wong, and J. M. Ko, "Statistical analysis of stress spectra for fatigue life assessment of steel bridges with structural health monitoring data," Engineering Structures, vol. 45, pp. 166-176, 2012.

[125] A. M. Freudenthal, "Safety of structures," Transactions of ASCE, vol. 112, pp. 125-180, 1947.

[126] R. Rackwitz and B. Flessler, "Structural reliability under combined random load sequences," Computers \& Structures, vol. 9, no. 5, pp. 489-494, 1978.

[127] P.-L. Liu and A. Der Kiureghian, "Finite element reliability of geometrically nonlinear uncertain structures," ASCE Journal of Engineering Mechanics, vol. 117, no. 8, pp. 1806-1825, 1991.

[128] P. C. Das, "Application of reliability analysis in bridge management," Engineering Structures, vol. 20, no. 11, pp. 957-959, 1998.

[129] D. M. Frangopol and K. Imai, "Geometrically nonlinear finite element reliability analysis of structural systems. II: applications," Computers \& Structures, vol. 77, no. 6, pp. 693-709, 2000.

[130] K. Imai and D. M. Frangopol, "Geometrically nonlinear finite element reliability analysis of structural systems. I: theory," Computers \& Structures, vol. 77, no. 6, pp. 677-691, 2000.
[131] M. G. Stewart, "Reliability-based assessment of ageing bridges using risk ranking and life cycle cost decision analyses," Reliability Engineering \& System Safety, vol. 74, no. 3, pp. 263-273, 2001.

[132] A. H. S. Ang and D. De Leon, "Modeling and analysis of uncertainties for risk-informed decisions in infrastructures engineering," Structure and Infrastructure Engineering, vol. 1, no. 1, pp. 19-31, 2005.

[133] P. Thoft-Christensen and M. J. Baker, Structural Reliability Theory and Its Applications, Springer, Berlin, Germany, 1982.

[134] D. Kececioglu, Reliability Engineering Handbook, vol. 1, Prentice-Hall, Englewood Cliffs, NJ, USA, 1991.

[135] O. Ditlevsen and H. O. Madsen, Structural Reliability Methods, John Wiley \& Sons, New York, NY, USA, 1996.

[136] A. Haldar and S. Mahadevan, Probability, Reliability, and Statistical Methods in Engineering Design, John Wiley \& Sons, New York, NY, USA, 2000.

[137] A. Haldar and S. Mahadevan, Reliability Assessment Using Stochastic Finite Element Analysis, John Wiley \& Sons, New York, NY, USA, 2000.

[138] B. M. Ayyub, R. H. McCuen, and Probability, Statistics, and Reliability for Engineers and Scientists, Chapman \& Hall/CRC, Boca Raton, Fla, USA, 2nd edition, 2003.

[139] J. E. Hurtado, Structural Reliability: Statistical Learning Perspectives, Springer, New York, NY, USA, 2004.

[140] J. Mohammadi and R. Polepeddi, "Bridge rating with consideration for fatigue damage from overloads," ASCE Journal of Bridge Engineering, vol. 5, no. 3, pp. 259-265, 2000.

[141] M. Lukić and C. Cremona, "Probabilistic assessment of welded joints versus fatigue and fracture," ASCE Journal of Structural Engineering, vol. 127, no. 2, pp. 211-218, 2001.

[142] W. G. Byers, M. J. Marley, J. Mohammadi, R. J. Nielsen, and S. Sarkani, "Fatigue reliability reassessment procedures: state-ofthe-art paper," ASCE Journal of Structural Engineering, vol. 123, no. 3, pp. 271-276, 1997.

[143] W. G. Byers, M. J. Marley, J. Mohammadi, R. J. Nielsen, and S. Sarkani, "Fatigue reliability reassessment applications: state-ofthe-art paper," ASCE Journal of Structural Engineering, vol. 123, no. 3, pp. 277-285, 1997.

[144] T.-L. Wang, C. Liu, D. Huang, and M. Shahawy, "Truck loading and fatigue damage analysis for girder bridges based on weighin-motion data," ASCE Journal of Bridge Engineering, vol. 10, no. 1, pp. 12-20, 2005.

[145] P. Chotickai and M. D. Bowman, "Truck models for improved fatigue life predictions of steel bridges," ASCE Journal of Bridge Engineering, vol. 11, no. 1, pp. 71-80, 2006.

[146] M. M. Szerszen, A. S. Nowak, and J. A. Laman, "Fatigue reliability of steel bridges," Journal of Constructional Steel Research, vol. 52, no. 1, pp. 83-92, 1999.

[147] P. H. Wirsching and J. T. P. Yao, "Statistical methods in structural fatigue," ASCE Journal of the Structural Division, vol. 96, no. 6, pp. 1201-1219, 1970.

[148] B. R. Ellingwood, "Fatigue reliability," ASCE Journal of the Structural Division, vol. 108, no. 1, pp. 3-23, 1982.

[149] X.-L. Zheng, B. Lü, and H. Jiang, "Determination of probability distribution of fatigue strength and expressions of $P-S-N$ curves," Engineering Fracture Mechanics, vol. 50, no. 4, pp. 483491, 1995.

[150] J. H. Yan, X. L. Zheng, and K. Zhao, "Prediction of fatigue life and its probability distribution of notched friction welded 
joints under variable-amplitude loading," International Journal of Fatigue, vol. 22, no. 6, pp. 481-494, 2000.

[151] H. Jakubczak, W. Sobczykiewicz, and G. Glinka, "Fatigue reliability of structural components," International Journal of Materials and Product Technology, vol. 25, no. 1-3, pp. 64-83, 2006.

[152] A. S. R. Murty, U. C. Gupta, and A. Radha, "A new approach to fatigue strength distribution for fatigue reliability evaluation," International Journal of Fatigue, vol. 17, no. 2, pp. 85-89, 1995.

[153] Y.-X. Zhao, Q. Gao, and J.-N. Wang, "An approach for determining an appropriate assumed distribution of fatigue life under limited data," Reliability Engineering \& System Safety, vol. 67, no. 1, pp. 1-7, 2000.

[154] S. Lorén, "Estimating fatigue limit distributions under inhomogeneous stress conditions," International Journal of Fatigue, vol. 26, no. 11, pp. 1197-1205, 2004.

[155] A. H. S. Ang and W. H. Munse, "Practical reliability basis for structural fatigue," in Proceedings of the ASCE National Structural Engineering Conference, New Orleans, La, USA, April 1975.

[156] W. H. Walker, "An interim report on studies of stress histories in highway bridges, volume I and II," Report No. UIUC-Eng-802005, University of Illinois at Urbana Champaign, Urbana, Ill, USA, 1978, Structural Research Series No. 448.

[157] K. Yamada and P. Albrecht, "Fatigue design of welded bridge details for service stresses," Transportation Research Record, vol. 607, pp. 25-30, 1976.

[158] C. G. Schilling, K. H. Klippstein, J. M. Barson, and G. T. Blake, "Fatigue of welded steel bridge members under variableamplitude loadings," NCHRP Report No. 188, Transportation Research Board, Washington, DC, USA, 1978.

[159] P. H. Wirsching, "Fatigue reliability for offshore structures," ASCE Journal of Structural Engineering, vol. 110, no. 10, pp. 2340-2356, 1984.

[160] H. O. Madsen, "Bayesian fatigue life prediction," in Probabilistic Method in the Mechanics of Solids and Structures, S. Eggwertz and N. C. Lind, Eds., pp. 395-406, Springer, Berlin, Germany, 1984.

[161] Y.-S. Park, S.-Y. Han, and B.-C. Suh, "Fatigue reliability analysis of steel bridge welding member by fracture mechanics method," Structural Engineering and Mechanics, vol. 19, no. 3, pp. 347-359, 2005.

[162] Y. Q. Ni, X. W. Ye, and J. M. Ko, "Modeling of stress spectrum using long-term monitoring data and finite mixture distributions," ASCE Journal of Engineering Mechanics, vol. 138, no. 2, pp. 175-183, 2011.

[163] Z. Zhao, A. Haldar, and F. L. Breen Jr., "Fatigue-reliability evaluation of steel bridges," ASCE Journal of Structural Engineering, vol. 120, no. 5, pp. 1608-1623, 1994.

[164] C. Crespo-Minguillón and J. R. Casas, "Fatigue reliability analysis of prestressed concrete bridges," ASCE Journal of Structural Engineering, vol. 124, no. 12, pp. 1458-1466, 1998.

[165] H.-N. Cho, J.-K. Lim, and H.-H. Choi, "Reliability-based fatigue failure analysis for causes assessment of a collapsed steel truss bridge," Engineering Failure Analysis, vol. 8, no. 4, pp. 311-324, 2001.

[166] S.-H. Kim, S.-W. Lee, and H.-S. Mha, "Fatigue reliability assessment of an existing steel railroad bridge," Engineering Structures, vol. 23, no. 10, pp. 1203-1211, 2001.

[167] M. S. Cheung and W. C. Li, "Probabilistic fatigue and fracture analyses of steel bridges," Structural Safety, vol. 25, no. 3, pp. 245-262, 2003.
[168] S. Pourzeynali and T. K. Datta, "Reliability analysis of suspension bridges against fatigue failure from the gusting of wind," Journal of Bridge Engineering, vol. 10, no. 3, pp. 262-271, 2005.

[169] M. Liu, D. M. Frangopol, and K. Kwon, "Fatigue reliability assessment of retrofitted steel bridges integrating monitored data," Structural Safety, vol. 32, no. 1, pp. 77-89, 2010.

[170] T. Guo, D. M. Frangopol, and Y. W. Chen, "Fatigue reliability assessment of steel bridge details integrating weigh-in-motion data and probabilistic finite element analysis," Computers \& Structures, vol. 112-113, pp. 245-257, 2012.

[171] A. Sahrapeyma, A. Hosseini, and M. S. Marefat, "Life-cycle prediction of steel bridges using reliability-based fatigue deterioration profile: case study of Neka Bridge," International Journal of Steel Structures, vol. 13, no. 2, pp. 229-242, 2013.

[172] B. M. Imam, T. D. Righiniotis, and M. K. Chryssanthopoulos, "Probabilistic fatigue evaluation of riveted railway bridges," ASCE Journal of Bridge Engineering, vol. 13, no. 3, pp. 237-244, 2008.

[173] K. Kwon and D. M. Frangopol, "Bridge fatigue reliability assessment using probability density functions of equivalent stress range based on field monitoring data," International Journal of Fatigue, vol. 32, no. 8, pp. 1221-1232, 2010.

[174] Y. Q. Ni, X. W. Ye, and J. M. Ko, "Monitoring-based fatigue reliability assessment of steel bridges: analytical model and application," ASCE Journal of Structural Engineering, vol. 136, no. 12, pp. 1563-1573, 2010.

[175] K. Kwon, D. M. Frangopol, and M. Soliman, "Probabilistic fatigue life estimation of steel bridges by using a bilinear $S-N$ approach," ASCE Journal of Bridge Engineering, vol. 17, no. 1, pp. 58-70, 2012.

[176] M. Soliman, D. M. Frangopol, and K. Kown, "Fatigue assessment and service life prediction of existing steel bridges by integrating SHM into a probabilistic bilinear $S-N$ approach," ASCE Journal of Bridge Engineering, vol. 139, no. 10, pp. 17281740, 2013.

[177] H. O. Madsen, "Probabilistic and deterministic models for predicting damage accumulation due to time varying loading," DIALOG 5-82, Danish Engineering Academy, Lyngby, Denmark, 1983.

[178] T. D. Righiniotis and M. K. Chryssanthopoulos, "Probabilistic fatigue analysis under constant amplitude loading," Journal of Constructional Steel Research, vol. 59, no. 7, pp. 867-886, 2003.

[179] A. Pipinato, C. Pellegrino, and C. Modena, "Fatigue assessment of highway steel bridges in presence of seismic loading," Engineering Structures, vol. 33, no. 1, pp. 202-209, 2011.

[180] C. S. Wang, L. Hao, and B. N. Fu, "Fatigue reliability updating evaluating of existing steel bridges," ASCE Journal of Bridge Engineering, vol. 17, no. 6, pp. 955-965, 2012.

[181] T. Guo and Y. W. Chen, "Fatigue reliability analysis of steel bridge details based on field-monitored data and linear elastic fracture mechanics," Structure and Infrastructure Engineering, vol. 9, no. 5, pp. 496-505, 2013. 


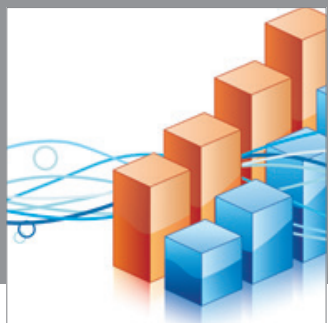

Advances in

Operations Research

mansans

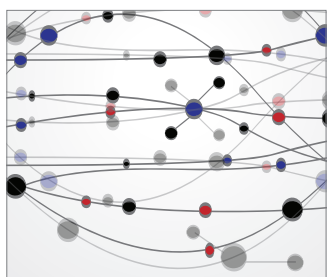

The Scientific World Journal
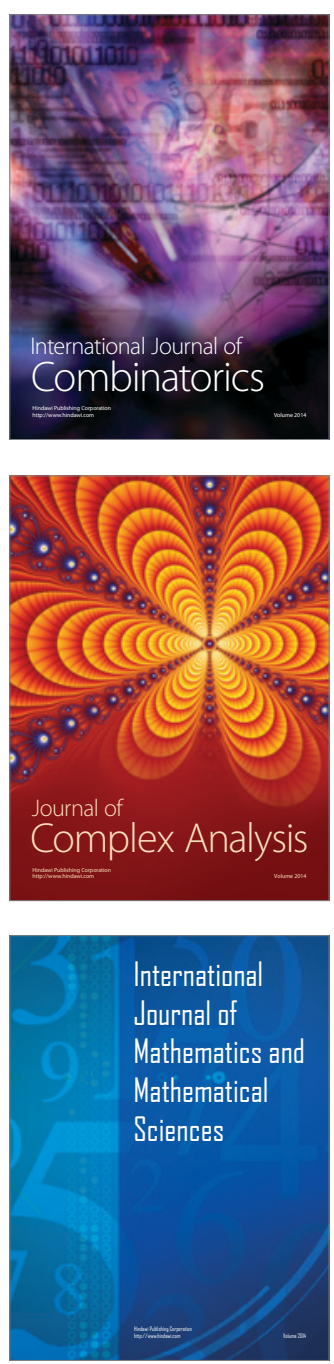
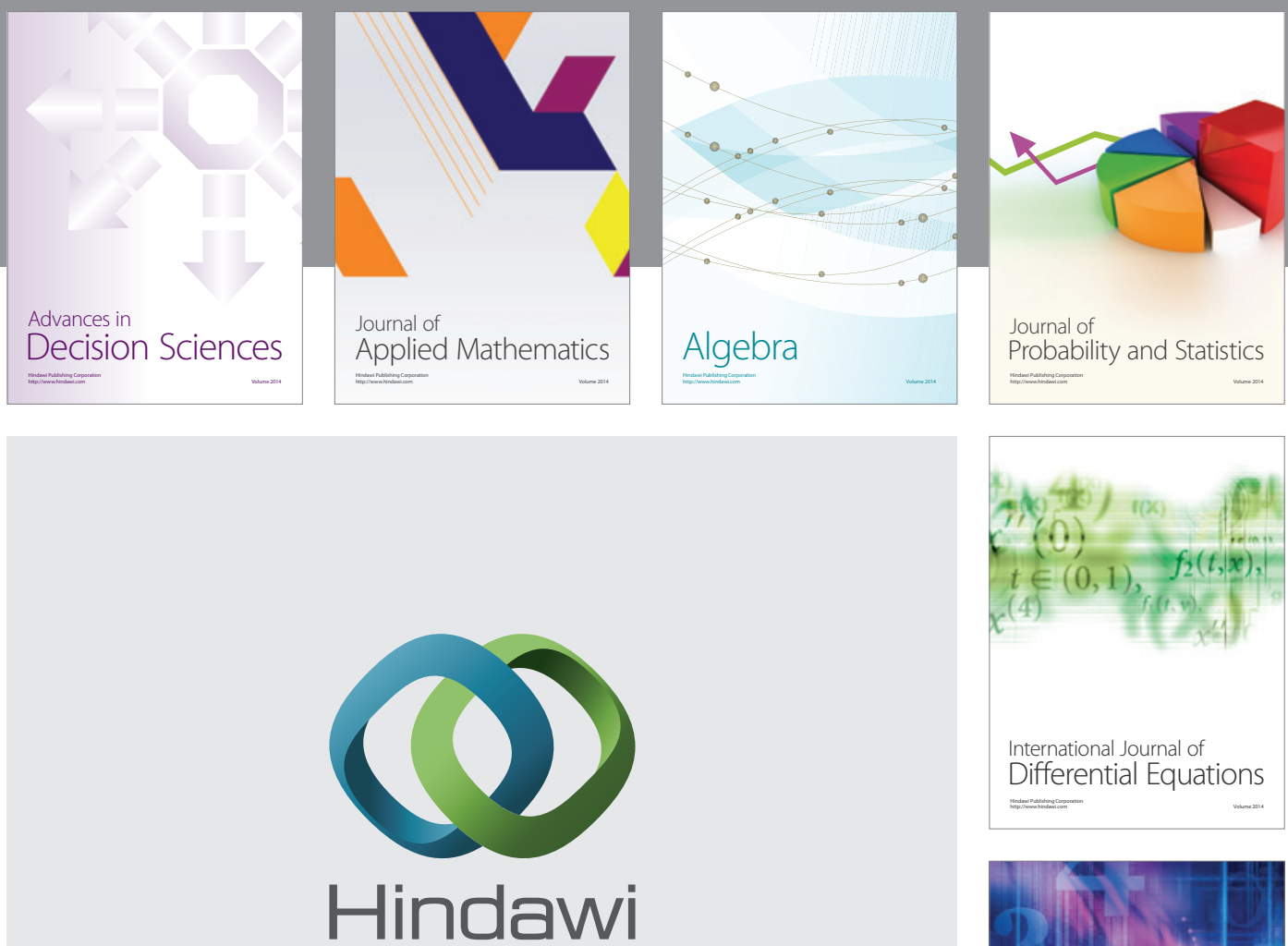

Submit your manuscripts at http://www.hindawi.com
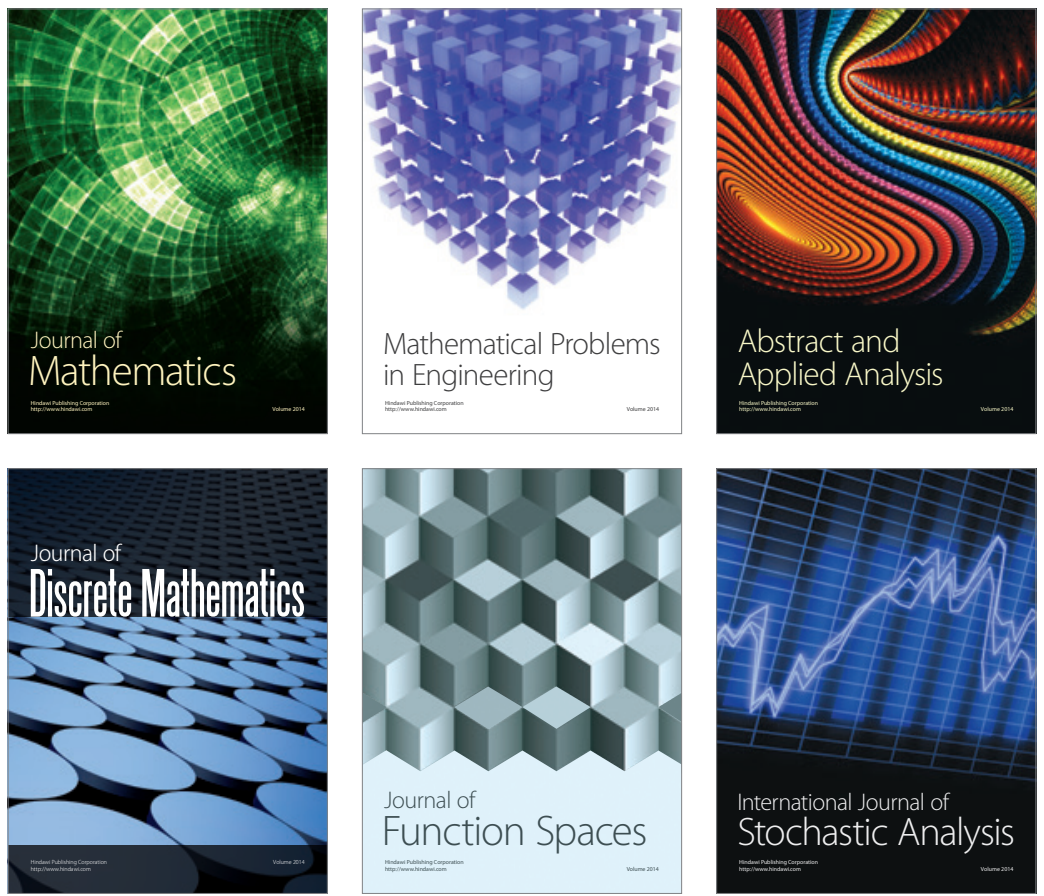

Journal of

Function Spaces

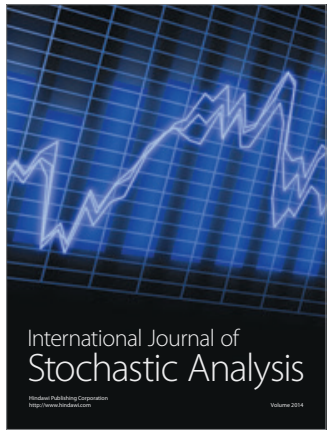

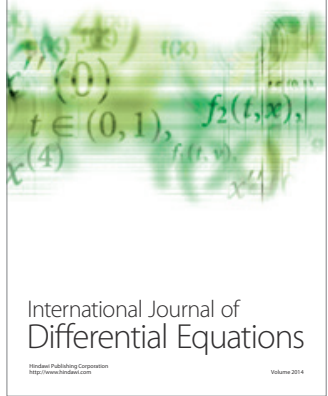
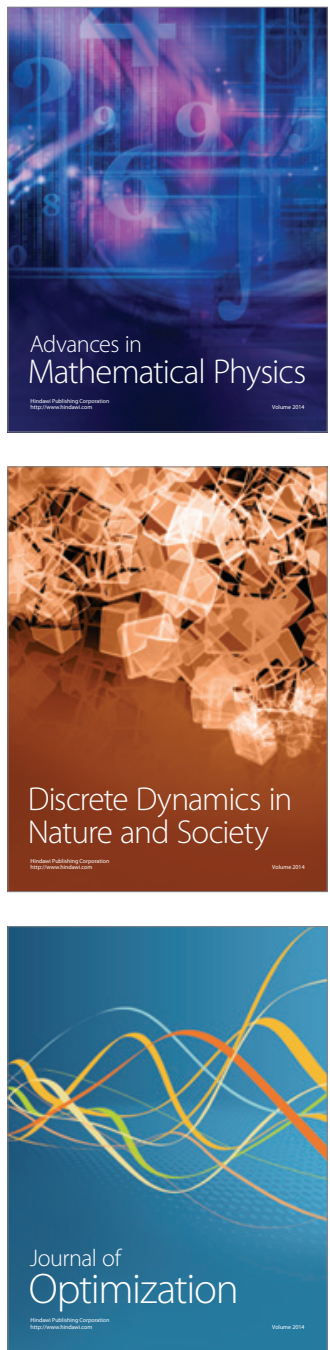